\title{
UJI KELAYAKAN SISTEM INFORMASI UNIT KESEHATAN SEKOLAH BERBASIS WEBSITE DI SMK MUHAMMADIYAH 1 BANTUL DENGAN FAKTOR KUALITAS MCCALL
}

\author{
Daya Prisandi Mandala \& Adi Dewanto \\ Universitas Negeri Yogyakarta \\ e-mail: daya.prisandi@gmail.com
}

\begin{abstract}
This research aims to determine the feasibility of Website Based Infirmary Information System at SMK Muhammadiyah 1 Bantul. The method is quantitative. The testing procedures is White-Box Testing, Black-Box Testing, Alpha Testing and Beta Testing. The object of this research is the Website Based Infirmary Information System at SMK Muhammadiyah 1 Bantul. Data was collected by questionnaire. Data wasanalyzed using quantitative data analysis. The obtainedresult from testing the feasibility of the Website Based Infirmary Information System at SMK Muhammadiyah 1 Bantul using McCall quality factor, is eligible as declared by the expert and very decent to use from users perspective.
\end{abstract}

Keywords: Information System, UKS, SMK Muhammadiyah 1 Bantul

\begin{abstract}
ABSTRAK
Penelitian ini bertujuan untukmengetahuitingkatkelayakan Sistem Informasi Unit Kesehatan Sekolah Berbasis Website di SMK Muhammadiyah 1 Bantul. Metode yang digunakan dalam penelitian ini adalahkuantitatif. Prosedur pengujiandalam penelitian ini adalah White-Box Testing, Black-Box Testing, Alpha Testing dan Beta Testing. Objek penelitian ini adalah perangkat lunak Sistem Informasi Unit Kesehatan Sekolah Berbasis Website di SMK Muhammadiyah 1 Bantul. Teknik pengumpulan data dilakukan dengan kuesioner. Analisis data menggunakan analisis data kuantitatif. Hasil penelitian yang diperolehdariujikelayakan terhadap Sistem Informasi Unit Kesehatan Sekolah Berbasis Website di SMK Muhammadiyah 1 Bantul dengan menggunakan faktor kualitas McCall, diperoleh hasil kelayakan oleh ahli menyatakan Layak dan pengguna menyatakan Sangat Layak untuk digunakan.
\end{abstract}

Kata Kunci: Sistem Informasi, UKS, SMK Muhammadiyah 1 Bantul

\section{PENDAHULUAN}

Sistem Informasi Unit Kesehatan Sekolah (UKS) Berbasis Website yang telah berhasil dikembangkan di SMK Muhammadiyah 1 Bantul merupakan sistem informasi yang digunakan dalam mengelola data yang ada di UKS. Data yang dikelola adalah data kunjungan, data riwayat sakit siswa, dan data obat. Aplikasi yang telah dikembangkan tersebut perlu dilakukan pengujian terhadap beberapa indikator penilaian kelayakan menurut faktor kualitas McCall yaitu: Correctness, Reliability, Efficiency, Integrity dan Usability, sehingga aplikasi tersebut dapat dikatakan layak untuk digunakan, selain itu pengujian ini dilakukan untuk menemukan kelemahan dan meningkatkan kualitas dari kinerja aplikasi yang dikembangkan.

Berdasarkan permasalahan tersebut, peneliti berencana akan melakukan Pengujian Sistem Informasi Unit Kesehatan Sekolah Berbasis Website di SMK Muhammadiyah 1 Bantul dengan Faktor Kualitas McCall. Pengujian yang dilakukan ini diharapkan dapat mengatasi masalah dan kendala yang terjadi pada SistemInformasi UKS di SMK Muhammadiyah 1 Bantul. 
Rumusan masalah pada penelitian ini adalah Bagaimana tingkat kelayakan Sistem Informasi Unit Kesehatan Sekolah Berbasis Website di SMK Muhammadiyah 1 Bantul? Penelitian ini bertujuan untuk mengetahui tingkat kelayakan dari Sistem Informasi Unit Kesehatan Sekolah Berbasis Website di SMK Muhammadiyah 1 Bantul dengan faktor kualitas McCall.
McCall dan kawan-kawan pada tahun 1977 telah mengusulkan suatu penggolongan atau pengelompokkan atas faktor-faktor atau kriteria yang mempengaruhi kualitas suatu software. Pada dasarnya McCall menitikberatkan faktor-faktor tersebut menjadi tiga aspek penting yaitu yang berhubungan dengan Product Operation, Product Revision, dan Product Trantition. (Wedhasmara, 2009: 104)

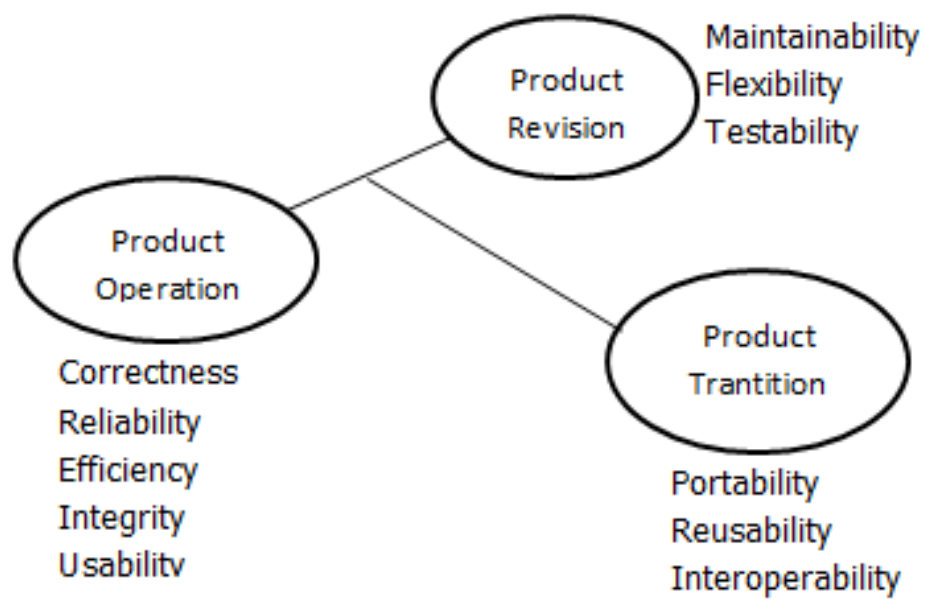

Gambar 1. Faktor Kualias Perangkat Lunak McCall (McCall, 1977: 2)

Berdasarkan gambar diatas terdapat tiga pengelompokkan faktor kualitas perangkat lunak yang dapat digunakan untuk mengukur tingkat kualitas atau kelayakan dari suatu perangkat lunak. Penelitian ini menggunakan faktor kualitas jenis Product Operation yang memiliki 5 indikator yaitu: (1) Correctness sejauh mana suatu software memenuhi spesifikasi dan Mission Objective dari pengguna; (2) Reliability tingkat dimana sebuah program dapat diharapkan melakukan fungsi yang diharapkan dengan ketelitian yang diminta; (3) Efficiency banyaknya sumber daya komputasi dan kode program yang dibutuhkan suatu software untuk melakukan fungsinya; (4) Integrity sejauh mana akses ke software dan data oleh pihak yang tidak berhak dapat dikendalikan; dan (5) Usability usaha yang diperlukan untuk mempelajari, mengoperasikan, menyiapkan input, dan mengartikan output dari software.
Untuk mengembangkan pengukuran langsung terhadap faktor kualitas tersebut digunakan serangkaian matrik untuk mengembangkan persamaan untuk masingmasing faktor sesuai dengan hubungan berikut:

$F q=c_{1} x m_{1}+c_{2} x m_{2}+\ldots+c_{n} x m_{n} \ldots$

Keterangan:

$F_{q}:$ faktor kualitas perangkat lunak

$c_{n}$ : koefisien regresi (bobot)

$m_{n}$ : matrik yang mempengaruhi perangkat lunak

Matrik tersebut dapat berbentuk checklist yang digunakan untuk menilai atribut spesifik dari perangkat lunak. Berikut ini adalah matrik yang digunakan dalam skema penilaian diantaranya, Access Audit, Access Control, Accuracy (akurasi), Communication commonality (kelaziman komunikasi), 
Completeness (kelengkapan), Consistency (konsistensi), Error tolerance (toleransi kesalahan), Execution efficiency (efisiensi eksekusi), Operability (operabilitas), Simplicity (kesederhanaan), Storage Efficiency, Traceability (traceabilitas), dan Training (pelatihan). Hubungan antara faktor kualitas dan matrik tersebut ditunjukkan pada gambar berikut ini.

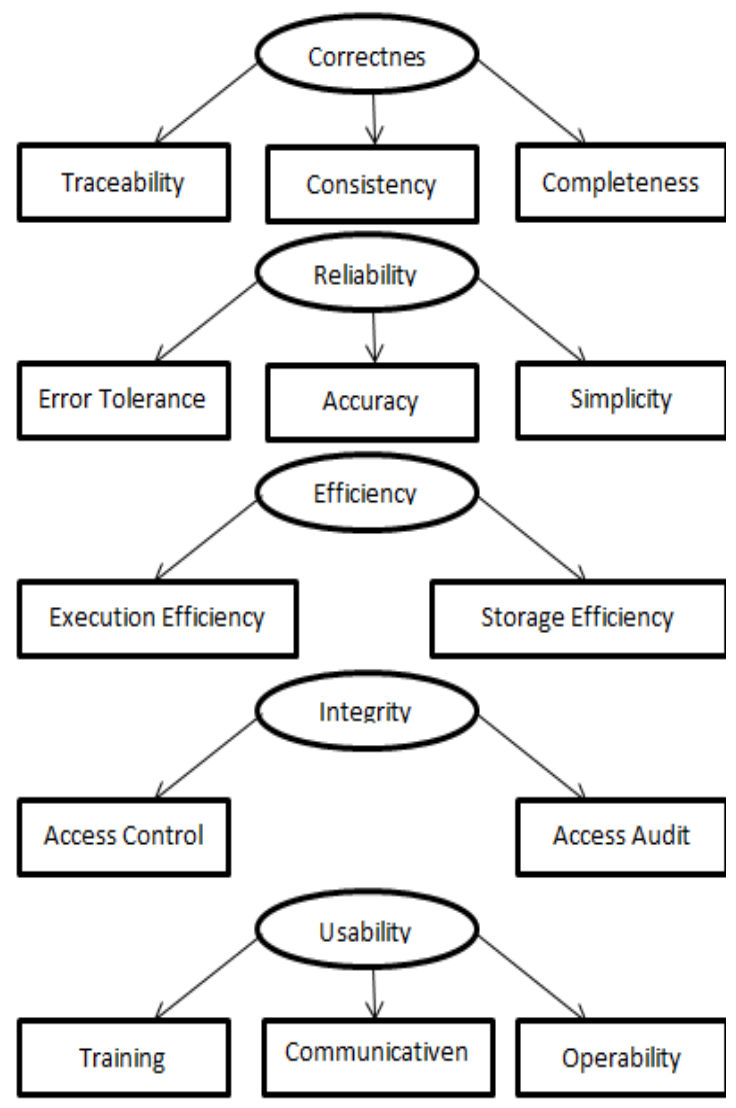

Gambar 2. Product Operation Hubungan

Kriteria dan Faktor Kualitas McCall(McCall, 1977: 2.10)

Berdasarkan hasil penelitian yang dilakukan oleh Aditya (2012) dengan judul penelitian "Perancangan Sistem Informasi Berbasis WEB SMKN 1 Poncol Kabupaten Magetan dengan Menggunakan PHP". Berdasarkan hasil penelitian yang dilakukan oleh Prima Aditya, menyatakan bahwa sistem informasi berbasis web dapat memberikan manfaat positif bagi sekolah karena dapat menjadikan media promosi dan publikasi serta informasi bagi alumni untuk mengetahui perkembangan sekolah. Selain itu penelitian yang dibuat oleh Ericko Dwi Cahyo (2009) dengan judul penelitian "Perancangan Sistem Informasi Berbasis WEB pada SMA Kartika I1Medan". Berdasarkan hasil penelitian Ericko Dwi Cahyo, menyatakan bahwa dengan adanya perancangan sistem informasi berbasis web dapat dilakukan dengan cepat, tepat dan akurat serta perancangan yang baik akan memudahkan dalam hal pengambilan keputusan sehingga dapat meningkatkan kinerja sekolah.

\section{METODE}

Penelitian ini menggunakan metode kuantitatif. Metode kuantitatif adalah metode penelitian yang berlandaskan pada filsafat positivism, digunakan untuk meneliti pada populasi atau sampel tertentu, pengumpulan data menggunakan instrument penelitian, analisis data bersifat kuantitatif/ statistik, dengan tujuan untuk menguji hipotesis yang telah ditetapkan (Sugiyono, 2015: 13). Penelitian ini dilakukan di SMK Muhammadiyah 1 Bantul yang ditujukan ke bagian Unit Kesehatan Sekolah. Peneliti merencanakan penelitian mulai dari bulan November 2016 sampai dengan bulan Februari 2017. Waktu ini meliputi kegiatan persiapan hingga penyusunan hasil penelitian. Objek penelitian ini adalah perangkat lunak Sistem Informasi Unit Kesehatan Sekolah Berbasis Website di SMK Muhammadiyah 1 Bantul dengan faktorkualitas McCall.

Prosedur pengujian dalam penelitian ini dilakukan dengan 4 pengujian diantaranya adalah: (1) White-Box Testing, pengujian terhadap tombol-tombol yang ada di aplikasi; (2) Black-Box Testing, pengujian terhadap fungsi-fungsi atau proses yang terjadi pada aplikasi; (3) Alpha Testing, pengujian terhadap produk versi Alpha; dan (4)Beta Testing,pengujian terhadap produk versi Beta. Data pada penelitian ini diperoleh dari hasil pengisian seperangkat alat intrumen berupa angket yang diberikan kepada sejumlah responden untuk menilai hasil kelayakan dari perangkat lunak yang dikembangkan. 
Teknik analisis data yang akan digunakan dalam penelitian ini adalah teknik analisis data kuantitatif. Data diperoleh dari hasil pengisian seperangkat alat instrument berupa angket yang diberikan kepada sejumlah responden untuk menilai hasil kelayakan dari perangkat lunak yang dikembangkan, kemudian data yang diperoleh dianalisis dengan menggunakan rumus dari kualitas McCall untuk memperoleh hasil uji kelayakan yang telah ditetapkan kedalam kategori kelayakan. Skala pengukuran yang digunakan dalam penelitian ini adalah skala Likert. Skala Likert merupakan metode pengukuran yang digunakan untuk mengukur sikap, pendapat, dan persepsi seseorang atau sekelompok orang tentang fenomena sosial (Sugiyono, 2011: 136). Skala pengukuran yang digunakan dapat dilihat pada Tabel 1 .

Tabel 1. Skala Likert

\begin{tabular}{lc}
\hline \multicolumn{1}{c}{ Kategori } & Skor \\
\hline Sangat Setuju & 5 \\
Setuju & 4 \\
Cukup Setuju & 3 \\
Tidak Setuju & 2 \\
Sangat Tidak Setuju & 1 \\
\hline
\end{tabular}

Tingkat kelayakan perangkat lunak diukur melalui persamaan Faktor Kualitas McCall, seperti berikut:

$$
F q=c 1 \times m 1+c 2 \times m 2+\ldots+c n \times m n
$$

\section{Keterangan:}

$F_{q}$ : faktor kualitas perangkat lunak

$c_{n}:$ koefisien regresi (bobot)

$m_{n}$ : matrik yang mempengaruhi perangkat lunak

Nilai Faktor Kualitas $(F q)$ yang diperoleh dari penghitungan kemudian diubah dalam bentuk persentase (\%). Besarnya persentase dihitung dengan persamaan berikut:

Persentase $=\frac{\text { Nilai yang didapat }}{\text { Nilai maksimal }}$ X $100 \% \ldots$ (3)
Selanjutnya, dari lima kategori yang ada di Tabel 1. dibuat skala menurut Arikunto (2008: 35), pembagian skala ini dilakukan dengan memperhatikan letak rentang bilangan. Sehingga pada Kondisi maksimal yang diharapkan adalah $100 \%$. Dari kondisi maksimal tersebut dibuat agar tiap kategori memiliki rentang persentase Antara nilai 1\% sampai dengan nilai $100 \%$ dibagi rata sehingga menghasilkan kategori kelayakan sistem seperti tabel berikut:

Tabel 2. Kategori Kelayakan Sistem

\begin{tabular}{ccc}
\hline No & Kategori & $\begin{array}{c}\text { Skor dalam } \\
\text { Persentase }\end{array}$ \\
\hline 1 & Sangat Layak & $81 \%-100 \%$ \\
2 & Layak & $61 \%-80 \%$ \\
3 & Cukup Layak & $41 \%-60 \%$ \\
4 & Tidak Layak & $21 \%-40 \%$ \\
5 & Sangat Tidak Layak & $-21 \%$ \\
\hline
\end{tabular}

\section{HASIL}

Data penelitian ini diperoleh dari hasil pengisian seperangkat instrumen berupa angket/kuesioner yang diberikan kepada sejumlah responden untuk menilai hasil kelayakan dari perangkat lunak yang dikembangkan. Sebelum responden melakukan pengisian terhadap instrumen penilaian yang diberikan, masing - masing responden terlebih dahulu melakukan uji coba terhadap Sistem Informasi Unit Kesehatan Sekolah Berbasis Website di SMK Muhammadiyah 1 Bantul yang telah dikembangkan. Pengujian pertama dilakukan oleh ahli melalui pengujian produk versi alpha dan menguji White-box dan Black-Box, selanjutnya pengujian dilakukan terhadap praktisi/pengguna melalui produk versi beta.

Data penilaian ini digunakan untuk menentukan tingkat kelayakan dari perangkat lunak Sistem Informasi Unit Kesehatan Sekolah Berbasis Website di SMK Muhammadiyah 1 Bantul. Adapun jumlah responden yang akan menentukan tingkat kelayakan dari perangkat lunak Sistem 
Informasi Unit Kesehatan Sekolah Berbasis Website di SMK Muhammadiyah 1 Bantul ini adalah sebanyak 34 orang yang terdiri dari 4 orang ahli yaitu 2 ahli media dan 2 ahli materi, 20 orang siswa dan 10 orang guru SMK Muhammadiyah 1 Bantul yang tergolong sebagai pengguna.

Hasil pengujian White-Box dan BlackBox Testing yang dilakukan oleh ahli diperoleh hasil bahwa semua tombol dan fungsi-fungsi atau proses yang terjadi di aplikasi Sistem Informasi Unit Kesehatan Sekolah Berbasis Website ini semua telah teruji dan berfungsi dengan baik.Hasil penghitungan dari indikator Correctness adalah sebagai berikut:

$$
\begin{aligned}
& \text { Correctness }=c_{1} \cdot m_{1}+c_{2} \cdot m_{2} \\
& =1 \cdot(4,6)+0,8 \text {. }(4) \\
& =4,6+3,2 \\
& =7,8 \\
& \text { Persentase }=\frac{\text { Nilai Yang Didapat }}{\text { Nilai Maksimal }} \times 100 \% \\
& =\frac{7,8}{10} \times 100 \% \\
& =78 \%
\end{aligned}
$$

Berdasarkan kategori kelayakan yang telah dijelaskan pada Tabel 2.Hasil penghitungan Correctness diatas, diperoleh persentase sebesar 78\% dengan kategori Layak. Hasil penghitungan dari indikator Reliability adalah sebagai berikut :

$$
\begin{aligned}
& \text { Reliability }=c_{1} \cdot m_{1}+c_{2} \cdot m_{2} \\
& =1 .(4,6)+0,8 \text {. }(4) \\
& =4,6+3,2 \\
& =7,8 \\
& \text { Persentase }=\frac{\text { Nilai Yang Didapat }}{\text { Nilai Maksimal }} \times 100 \% \\
& =\frac{7,8}{10} \times 100 \% \\
& =78 \%
\end{aligned}
$$

Berdasarkan kategori kelayakan yang telah dijelaskan pada Tabel 2. Hasil penghitungan Reliability diatas, diperoleh persentase sebesar 78\% dengan kategori Layak. Hasil penghitungan dari indikator Efficiency adalah sebagai berikut :

$$
\begin{aligned}
& \begin{aligned}
\text { Efficiency } & =c_{1} \cdot m_{1}+c_{2} \cdot m_{2} \\
& =1 \cdot(4)+0,8 \cdot(4,5) \\
& =4+3,6 \\
& =7,6
\end{aligned} \\
& \text { Persentase }= \\
& =\frac{\text { Nilai Yang Didapat }}{\text { Nilai Maksimal }} \times 100 \% \\
& =\frac{7,6}{10} \times 100 \% \\
& =76 \%
\end{aligned}
$$

Berdasarkan kategori kelayakan yang telah dijelaskan pada Tabel 2.Hasil penghitungan Efficiency diatas, diperoleh persentase sebesar $76 \%$ dengan kategori Layak. Hasil penghitungan dari indikator Integrity adalah sebagai berikut :

$$
\begin{gathered}
\text { Integrity } \quad=c_{1} \cdot m_{1}+c_{2} \cdot m_{2} \\
=1 \cdot(4)+0,8 \cdot(4,5) \\
=4+3,6 \\
=7,6
\end{gathered}
$$

Berdasarkan kategori kelayakan yang telah dijelaskan pada Tabel 2. Hasil penghitungan Integrity diatas, diperoleh persentase sebesar $76 \%$ dengan kategori Layak. Hasil penghitungan dari indikator Usability adalah sebagai berikut : 


$$
\begin{aligned}
\text { Usability }= & c_{1} \cdot m_{1} \\
& +c_{2} \cdot m_{2} \\
= & 0,8 \cdot(4,5)+1 \cdot(4,5) \\
= & 3,6+4,5 \\
= & 8,1 \\
\text { Persentase }= & \frac{\text { Nilai Yang Didapat }}{\text { Nilai Maksimal }} \times 100 \% \\
= & \frac{8,1}{10} \times 100 \% \\
= & 81 \%
\end{aligned}
$$

Berdasarkan kategori kelayakan yang telah dijelaskan pada Tabel 2. Hasil penghitungan Usability diatas, diperoleh persentase sebesar $81 \%$ dengan kategori Sangat Layak. Penghitungan data hasil uji kelayakan indikator Correctness oleh 9 orangpengguna adalah sebagai berikut:

$$
\begin{aligned}
& \text { Correctness } \\
= & c_{1} \cdot m_{1}+c_{2} \cdot m_{2}+c_{3} \cdot m_{3} \\
= & 1 \cdot(5)+0,8 \cdot(5)+0,8 \cdot(5) \\
= & 5+4+4 \\
= & 13
\end{aligned}
$$

$$
\begin{aligned}
\text { Persentase }= & \frac{\text { Nilai Yang Didapat }}{\text { Nilai Maksimal }} \times 100 \% \\
& =\frac{13}{15} \times 100 \% \\
& =86,66 \%
\end{aligned}
$$

Dari hasil uji kelayakan terhadap indikator Correctness dari pengguna, diperoleh hasil persentase kelayakan seperti pada Tabel 3.

Tabel 3. Kategori Kelayakan Correctness

\begin{tabular}{ccl}
\hline \multicolumn{3}{c}{ Correcctness } \\
\hline Jumlah & $\begin{array}{c}\text { Persentase } \\
(\%)\end{array}$ & Kategori \\
Pengguna & 86,66 & Sangat \\
\hline 9 orang & 83,33 & Layak \\
5 orang & 81,33 & \\
5 orang & 80 & \\
1 orang & 78,66 & Layak \\
1 orang & 76 & \\
5 orang & 74,66 & \\
4 orang & & \\
\hline
\end{tabular}

Berdasarkan tabel diatas diperoleh hasil persentase kategori kelayakan untuk indikator Correctness dengan rincian 19 orang pengguna menyatakan Sangat Layak dan 11 orang pengguna menyatakan Layak. Sehingga dapat disimpulkan bahwa mayoritas pengguna $(63,33 \%)$ menyatakan Sistem Informasi Unit Kesehatan Sekolah Berbasis Website di SMK Muhammadiyah 1 Bantul ini Sangat Layak. Penghitungan data hasil uji kelayakan indikator Reliability5 orang pengguna adalah sebagai berikut.

$$
\begin{aligned}
& \text { Reliability } \\
= & c_{1} \cdot m_{1}+c_{2} \cdot m_{2}+c_{3} \cdot m_{3} \\
= & 1 \cdot(5)+0,8 \cdot(5)+0,8 \cdot(5) \\
= & 5+4+4 \\
= & 13
\end{aligned}
$$

$$
\begin{aligned}
\text { Persentase }= & \frac{\text { Nilai Yang Didapat }}{\text { Nilai Maksimal }} \times 100 \% \\
& =\frac{13}{15} \times 100 \% \\
& =86,66 \%
\end{aligned}
$$

Dari hasil uji kelayakan indikator Reliability dari pengguna, diperoleh hasil persentase kelayakan seperti pada Tabel 4.

Tabel 4. Kategori Kelayakan Reliability

\begin{tabular}{ccc}
\hline & Reliability & \\
\hline Jumlah & $\begin{array}{c}\text { Persentase } \\
(\%)\end{array}$ & Kategori \\
Pengguna & 86,66 & Sangat \\
\hline 5 orang & 81,33 & Layak \\
12 orang & 80 & \\
1 orang & 78,66 & \\
3 orang & 77,33 & Layak \\
1 orang & 74,66 & \\
5 orang & 72,1 & \\
1 orang & 69,33 & \\
2 orang & & \\
\hline
\end{tabular}

Berdasarkan tabel diatas diperoleh hasil persentase kategori kelayakan untuk indikator Reliability dengan rincian 17 orang pengguna menyatakan Sangat Layak dan 13 orang pengguna menyatakan Layak. Sehingga dapat disimpulkan bahwa mayoritas pengguna $(56,66 \%)$ menyatakan Sistem Informasi Unit 
Kesehatan Sekolah Berbasis Website di SMK Muhammadiyah 1 Bantul ini Sangat Layak. Penghitungan data hasil uji kelayakan indikator Efficiency dari 4 orang pengguna dengan hasil penilaian seperti berikut.

$$
\begin{aligned}
& \begin{aligned}
\text { Efficiency } & =c_{1} \cdot m_{1}+c_{2} \cdot m_{2} \\
& =0,8 \cdot(5)+1 \cdot(5) \\
& =4+5 \\
& =9
\end{aligned} \\
& \begin{aligned}
\text { Persentase }= & \frac{\text { Nilai Yang Didapat }}{\text { Nilai Maksimal }} \times 100 \% \\
& =\frac{9}{10} \times 100 \% \\
& =90 \%
\end{aligned}
\end{aligned}
$$

Dari hasil uji kelayakan indikator Efficiencydari pengguna, diperoleh hasil persentase kelayakan seperti pada Tabel 5.

Tabel 5. Kategori Kelayakan Efficiency

\begin{tabular}{ccc}
\hline \multicolumn{3}{c}{ Efficiency } \\
\hline Jumlah & Persentase (\%) & Kategori \\
Pengguna & & \\
\hline 4 orang & 90 & Sangat \\
7 orang & 86 & Layak \\
5 orang & 82 & \\
3 orang & 81 & \\
5 orang & 80 & Layak \\
1 orang & 77 & \\
2 orang & 76 & \\
3 orang & 72 & \\
\hline
\end{tabular}

Berdasarkan tabel diatas diperoleh hasil persentase kategori kelayakan untuk indikator Efficiency dengan rincian 19 orang pengguna menyatakan Sangat Layak dan 11 orang pengguna menyatakan Layak. Sehingga dapat disimpulkan bahwa mayoritas penguna $(63,33 \%)$ menyatakan Sistem Informasi Unit Kesehatan Sekolah Berbasis Website di SMK Muhammadiyah 1 Bantul ini Sangat Layak.

Penghitungan data hasil uji kelayakan indikator Integrity dari Ibu Tunggal Winata dengan hasil penilaian yang sama seperti berikut.

$$
\begin{aligned}
& \text { Integrity }=c_{1} \cdot m_{1}+c_{2} \cdot m_{2} \\
& =0,8 \text {. (5) }+1 \text {. (5) } \\
& =4+5 \\
& =9 \\
& \text { Persentase }=\frac{\text { Nilai Yang Didapat }}{\text { Nilai Maksimal }} \times 100 \% \\
& =\frac{9}{10} \times 100 \% \\
& =90 \%
\end{aligned}
$$

Dari hasil uji kelayakan indikator Integritydari guru, diperoleh hasil persentase kelayakan seperti pada Tabel 6 .

Tabel 6. Kategori kelayakan Integrity

\begin{tabular}{ccc}
\hline \multicolumn{3}{c}{ Integrity } \\
\hline Jumlah & $\begin{array}{c}\text { Persentase } \\
(\%)\end{array}$ & Kategori \\
Pengguna & 90 & \\
\hline 3 orang & 86 & Sangat \\
5 orang & 85 & Layak \\
1 orang & 82 & \\
2 orang & 81 & \\
2 orang & 80 & \\
6 orang & 77 & Layak \\
1 orang & 76 & \\
4 orang & 72 & \\
3 orang & & \\
\hline
\end{tabular}

Berdasarkan tabel diatas diperoleh hasil persentase kategori kelayakan untuk indikator Efficiency dengan rincian 13 orang pengguna menyatakan Sangat Layak dan 17 orang pengguna menyatakan Layak. Sehingga dapat disimpulkan bahwa mayoritas pengguna $(56,66 \%)$ menyatakan Sistem Informasi Unit Kesehatan Sekolah Berbasis Website di SMK Muhammadiyah 1 Bantul ini Layak.

Penghitungan data hasil uji kelayakan indikator Usability dari 4 orang pengguna dengan hasil penilaian yang sama seperti berikut. 


$$
\begin{gathered}
\begin{aligned}
\text { Usability } & = \\
= & c_{1} \cdot m_{1}+c_{2} \cdot m_{2}+c_{3} \cdot m_{3} \\
= & 0,8 \cdot(5)+1 \cdot(5)+0,8 \cdot(5) \\
= & 4+5+4 \\
= & 13
\end{aligned} \\
\begin{aligned}
\text { Persentase } & =\frac{\text { Nilai Yang Didapat }}{\text { Nilai Maksimal }} \times 100 \% \\
& =\frac{13}{15} \times 100 \% \\
& =86,66 \%
\end{aligned}
\end{gathered}
$$

Dari hasil uji kelayakan indikator Usabilitydari guru, diperoleh hasil persentase kelayakan seperti pada tabel berikut:

Tabel 7. Kategori Kelayakan Usability

\begin{tabular}{ccc}
\hline \multicolumn{3}{c}{ Usability } \\
\hline Jumlah & $\begin{array}{c}\text { Persentase } \\
(\%)\end{array}$ & Kategori \\
Pengguna & 86,66 & Sangat \\
\hline 4 orang & 81,33 & Layak \\
2 Orang & 80 & \\
3 orang & 78 & \\
1 orang & 76 & Layak \\
9 orang & 74,66 & \\
2 orang & 69,33 & \\
9 orang & & \\
\hline
\end{tabular}

Berdasarkan tabel diatas diperoleh hasil persentase kategori kelayakan untuk indikator Usability dengan rincian 6 orang pengguna menyatakan Sangat Layak dan 24 orang guru menyatakan Layak. Sehingga dapat disimpulkan bahwa mayoritas guru (80\%) menyatakan Sistem Informasi Unit Kesehatan Sekolah Berbasis Website di SMK Muhammadiyah 1 Bantul ini Layak..

\section{SIMPULAN}

Berdasarkan hasil analisis data hasil uji kelayakan terhadap Sistem Informasi Unit Kesehatan Sekolah Berbasis Website di SMK Muhammadiyah 1 Bantul dengan menggunakan faktor kualitas McCall, diperoleh hasil kelayakan oleh ahli dari indikator Correctness sebesar $78 \%$ dengan kategori Layak, dari indikator Reliability diperoleh persentase sebesar $78 \%$ dengan kategori Layak, dari indikator Efficiency diperoleh persentase sebesar $76 \%$ dengan kategori Layak, dari indikator Integrity diperoleh persentase sebesar $76 \%$ dengan kategori Layak, dan dari indikator Usability diperoleh hasil persentase sebesar $81 \%$ dengan kategori Sangat Layak.

Sedangkan hasil penilaian kelayakan yang diberikan oleh pengguna dari indikator Corretness diperoleh persentase sebesar 63,33\% menyatakan Sistem Informasi Unit kesehatan Sekolah Berbasis Website ini Sangat Layak, dari indikator Reliability diperoleh hasil persentase sebesar 56,66\% pengguna menyatakan Sistem Infromasi Unit Kesehatan Sekolah Berbasis Website ini Sangat Layak, selanjutnya dari indikator Efficiency diperoleh hasil persentase dari pengguna sebesar 63,33\% menyatakan Sistem Informasi Unit Kesehatan Sekolah Berbasis Website ini Sangat Layak, selanjutnya dari indikator Integrity diperoleh hasil persentase dari pengguna sebesar $56,66 \%$ menyatakan layak, dan untuk indikator Usability diperoleh hasil persentase kelayakan dari pengguna sebesar 80\% Menyatakan Sistem Informasi Unit Kesehatan Sekolah Berbasis Website ini layak. Dari hasil penilaian oleh pihak praktisi atau pengguna aplikasi tersebut dapat diambil kesimpulan bahwa Sistem Informasi Unit Kesehatan Sekolah Berbasis Website di SMK Muhammadiyah 1 bantul Sangat Layak untuk digunakan.

Saran yang dapat peneliti berikan berkaitan dengan Pengembangan Sistem Informasi Unit Kesehatan Sekolah Berbasis Website di SMK Muhammadiyah 1 Bantul dan juga sistem informasi lain yang berbasis web di lingkungan SMK Muhammadiyah 1 Bantul adalah (1) Menambahkan fitur recaptcha untuk melakukan login agar keamanan sistem lebih terjamin. (2) Memberikan batasan akses kepada setiap pengguna agar ketika user tidak melakukan logout dalam waktu tertentu session akan di logout otomatis. 


\section{DAFTAR PUSTAKA}

Aditya, P. (2012). Perancangan Sistem Informasi Berbasis WEB SMKN 1 Poncol Kabupaten Magetan dengan Menggunakan PHP. SKRIPSI, Universitas Muhammadiyah Ponorogo.

Arikunto, S. (2008). Evaluasi Program Pendidikan: Pedoman Teoritis Praktis Bagi Mahasiswa dan Praktisi Pendidikan. Jakarta: Bumi Aksara.

Cahyo, E. D. (2009). Perancangan Sistem Informasi Berbasis WEB pada SMA Kartika I-1 Medan. SKRIPSI, Universitas Sumatera Utara.
McCall J. A., Richards. \& Walters. (1977). Factors In Software Quality. New York: General Electric Company.

Sugiyono, P. D. (2011). Metode Penelitian Kombinasi (Mixed Methods). Bandung: Alfabeta

Sugiyono. 2015. Metode penelitian dan pengembangan. Yogyakarta: Alfabeta

Wedhasmara, A. 2009. Memasyarakatkan dan memperoleh concern akan software quality, sebagai faktor pendorong penerapan CMMI atau CMM-SW. Jurnal Sistem Informasi, I No 3, 104 